\title{
AVALIAÇÃO DO TRATAMENTO PRESERVATIVO DE TALISCAS DE BAMBU COM ÁCIDO PIROLENHOSO
}

\author{
Jéssica Harue Matsuoka $^{1}$, Antonio Ludovico Beraldo ${ }^{2}$ \\ ${ }^{1}$ Bióloga, M.Sc., Depto. de Construções Rurais, UNICAMP, Campinas, SP, Brasil - matsuoka.jessica@ gmail.com
}

${ }^{2}$ Eng. Agrícola, Dr., FEAGRI/UNICAMP, Campinas, SP, Brasil - beraldo@ feagri.unicamp.br

Recebido para publicação: 14/12/2012 - Aceito para publicação: 04/10/2013

\begin{abstract}
Resumo
A baixa resistência natural do bambu ao ataque de organismos xilófagos constitui uma das principais limitações ao seu pleno uso. O objetivo do presente estudo foi avaliar o efeito do ácido pirolenhoso no tratamento preservativo de taliscas de bambu-gigante contra fungos deterioradores. Para tal, foi realizado um ensaio de apodrecimento acelerado em laboratório com taliscas testemunhas (sem tratamento) e taliscas tratadas com o produto diluído em água fervente nas concentrações $0 \%, 5 \%$, $10 \%, 20 \%$ e $30 \%$, adotando-se tempos de imersão 15, 45, 90 e 180 minutos. As taliscas de bambu foram testadas após 6 e 16 semanas de exposição. Foram efetuadas inspeções visuais nas taliscas e aplicados ensaios não destrutivos de perda de massa e por ultrassom (6 e 16 semanas) e ensaios de flexão estática (após 16 semanas). Os resultados obtidos nos ensaios não destrutivos não evidenciaram o efeito dos fatores testados (tipo de solo, duração do tratamento e concentração da solução) nessas propriedades. A análise visual indicou apenas um ataque superficial nas taliscas, não evidenciando perda de massa. No ensaio de flexão estática, verificou-se o efeito favorável da duração do tratamento nos módulos de elasticidade $\left(\mathrm{E}_{\mathrm{m} 0}\right)$ e de ruptura (MOR). O tipo de solo (natural ou estéril) não apresentou influência no módulo de elasticidade, enquanto que a concentração da solução não influenciou o módulo de ruptura.

Palavras-chave: Bambu-gigante; biodeterioração; fungos deterioradores.
\end{abstract}

\begin{abstract}
Evaluation of preservative treatment of bamboo strips with pyroligneous acid. Bamboo presents a low natural resistance to decay, which constitutes one of the major limitations to its use. This study aims to evaluate pyroligneous acid effect against fungal bamboo deterioration through an accelerated laboratory decay with testing reference (without treatment) and treated specimens with the product diluted in boiling water at $(0 \%, 5 \%, 10 \%, 20 \%$ and $30 \%)$ in different immersion times $(15,45,90$, and 180 minutes). Bamboo splits were evaluated after 6 and 16 weeks of exposure. Visual inspections and non-destructive tests (mass loss and ultrasound at 6 and 16 weeks) and bending (after 16 weeks) were applied to the bamboo strips. Results of the non-destructive tests did not allow to detect the effect of the factors (soil type, immersion time and solution concentration) on these properties. Only a superficial attack was observed by visual inspection, which did not denote mass loss. Immersion time shows a positive effect on modulus of elasticity $\left(\mathrm{E}_{\mathrm{m} 0}\right)$ and on modulus of rupture (MOR). Moduli of elasticity and rupture were not influenced by soil type (sterile or natural), or by the concentration of the solution, respectively.

Keywords: Giant bamboo; biodeterioration; fungi decay.
\end{abstract}

\section{INTRODUÇÃO}

De origem asiática, o bambu-gigante, como é popularmente conhecido, apresenta considerável resistência mecânica e excelentes propriedades físicas, como leveza, teor de fibras, flexibilidade e facilidade de trabalho, o que permite seu uso em diversas aplicações. Por se tratar de um material renovável, o bambu apresenta grande potencial como matéria-prima industrial, sobretudo no ramo da movelaria, onde se destaca o uso da espécie Dendrocalamus giganteus Munro (PEREIRA; BERALDO, 2008). 
Uma possibilidade de utilização do bambu é na fabricação de painéis com lâminas serradas, aplainadas e coladas (bambu laminado colado - BLC), para utilização em divisórias, forros, pisos, móveis e revestimentos (RIVERO, 2003).

No entanto, uma das maiores preocupações quanto ao uso do bambu é a sua alta vulnerabilidade ao ataque de organismos xilófagos (ESPELHO; BERALDO, 2008), o que diminui consideravelmente sua vida útil e pode gerar grandes prejuízos econômicos, sendo os insetos e os fungos os principais agentes que degradam o bambu.

Tais fungos se dividem em cinco categorias: podridão branca, podridão parda, podridão mole, manchadores e bolores. Apesar de não comprometerem significativamente, em um período inicial, a resistência mecânica do bambu, os fungos manchadores e os bolores influenciam na durabilidade e na resistência ao impacto, diminuindo o valor comercial dos colmos e dos produtos derivados desse material (ALVES; MENDES, 2002). Essa degradação do bambu constitui uma grande preocupação, sobretudo na indústria moveleira, devido ao forte apelo estético que deverão apresentar os produtos à base de bambu.

Com o intuito de prolongar sua vida útil e aumentar sua resistência à deterioração por insetos e fungos, normalmente o bambu é submetido a um tratamento preservativo, o qual pode ser natural ou químico. Entre os inúmeros tipos e métodos existentes, o tratamento químico é o mais utilizado no controle dos agentes deterioradores do bambu, por ser considerado o mais eficaz. Entre os produtos químicos mais utilizados no tratamento do material para produção em larga escala estão o CCA (arseniato de cobre cromatado) e o CCB (borato de cobre cromatado).

No entanto, devido aos riscos inerentes ao meio ambiente que os produtos químicos podem causar e à crescente demanda por produtos e técnicas que minimizem o impacto ambiental, torna-se necessária a busca por produtos alternativos que reúnam características desejadas para um bom preservativo (eficiência, baixo custo e impacto ambiental mínimo). Sob tais aspectos, o ácido pirolenhoso apresenta-se como um produto preservativo com grande potencial para proteger materiais lignocelulósicos da biodeterioração.

O ácido pirolenhoso, por ser obtido da recuperação e da condensação de gases voláteis gerados durante o processo de fabricação de carvão vegetal, evita o desperdício de material e diminui a poluição, por permitir que sejam reaproveitados subprodutos que normalmente seriam desprezados e liberados no meio ambiente sob a forma de fumaça (SOUZA-SILVA et al., 2005; PORTO et al., 2007). Além disso, o ácido pirolenhoso é considerado um produto promissor para utilização na agricultura no controle de pragas e doenças (ZANETTI et al., 2003), por suas propriedades fungicidas, dentre outras, além do baixo custo.

Uma das possibilidades de testar a eficiência de um determinado tratamento preservativo aplicado ao bambu seria a avaliação de sua resistência mecânica após períodos de exposição. No entanto, a aplicação de ensaio destrutivo inviabiliza futuras avaliações passíveis de serem aplicadas no mesmo material. Por esse motivo, para avaliar um material sem que seja causada uma modificação significativa de suas características, são empregados ensaios denominados não destrutivos (END), que constituem uma das principais ferramentas do controle de qualidade de materiais e produtos, contribuindo para aumentar a confiabilidade da avaliação. Dentre os diversos tipos de ensaios não destrutivos, destacam-se a inspeção visual e a avaliação por perda de massa e por ultrassom, os quais foram utilizados no presente estudo para detectar uma possível degradação das taliscas de bambu.

A técnica do ultrassom consiste em medir o tempo que uma onda ultrassônica necessita para atravessar um sólido. Diversos são os fatores que podem influenciar a magnitude dessa velocidade. Ao se analisarem materiais lignocelulósicos, tais como a madeira e o bambu, a direção anatômica considerada para a propagação das ondas (longitudinal, radial ou tangencial) e a presença de defeitos, tais como falhas naturais ou aquelas devidas ao ataque exercido por agentes biológico, podem alterar a velocidade do pulso ultrassônico (VPU).

Constituiu o objetivo deste trabalho avaliar, por meio de ensaios destrutivo (flexão estática) e não destrutivos (variação de massa e velocidade do pulso ultrassônico), o desempenho de taliscas de bambu-gigante tratadas com ácido pirolenhoso após serem submetidas ao ensaio de degradação acelerada, após 6 e 16 semanas de exposição.

\section{MATERIAL E MÉTODOS}

\section{Tratamento com ácido pirolenhoso}

As taliscas (réguas) de bambu-gigante foram usinadas e fornecidas pela empresa Oré Brasil, situada em Santa Catarina, que adquire os colmos de diversos produtores, que são, posteriormente, 
redimensionados em lâminas com aproximadamente $15 \times 2,0 \times 0,6 \mathrm{~cm}$. As taliscas utilizadas eram originalmente destinadas à fabricação de móveis de bambu laminado colado (BLC) nessa indústria. Desse modo, passavam inicialmente por um processo mecânico que visava eliminar duas regiões da talisca: a primeira, próxima à camada interna; a segunda, próxima à casca (camada externa). Pode-se considerar que, após o beneficiamento, as taliscas assim produzidas estavam "melhoradas" mecanicamente, ou seja, não apresentavam as camadas mais suscetíveis à degradação, que são as camadas internas da parede do colmo original.

$\mathrm{O}$ ácido pirolenhoso, também fornecido pela mesma empresa, foi adquirido de um produtor de carvão vegetal catarinense, que utiliza como matéria-prima diversas espécies não especificadas de madeiras da região.

Para o tratamento das taliscas, utilizou-se o método de imersão em ácido pirolenhoso diluído em água destilada (Figura 1), nas seguintes condições: concentrações de 0\% (puro), 5\%, 10\%, 20\% e 30\%; tempos de imersão de 15, 45, 90 e 180 minutos, em temperatura de ebulição. Para cada variável, foram utilizados 10 corpos de prova, além de 10 corpos de prova considerados testemunhas (sem tratamento). Após o tratamento, os corpos de prova foram secos em estufa a $103{ }^{\circ} \mathrm{C}$ por um período de $24 \mathrm{~h}$ e então foram pesados, medidos, e submetidos ao ensaio de ultrassom, para serem, posteriormente, acondicionados ao ensaio acelerado de laboratório.
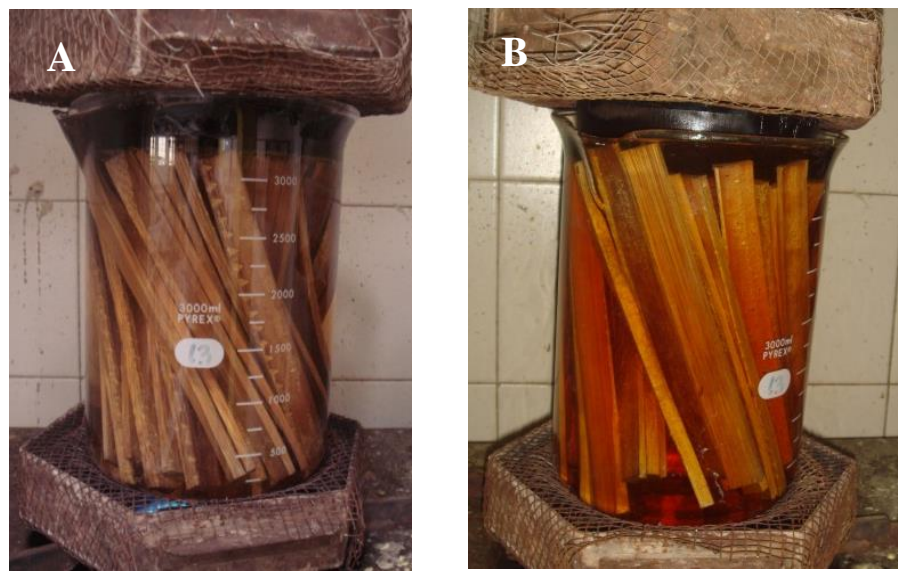

A - Concentração de 5\%; B - Concentração de $20 \%$.

Figura 1. Corpos de prova de bambu imersos em soluções de ácido pirolenhoso.

Figure 1. Bamboo specimens soaked in pyroligneous solutions.

\section{Ensaio acelerado de laboratório}

Os corpos de prova tratados e a testemunha, após estarem estabilizados em ambiente de laboratório (temperatura média de $25{ }^{\circ} \mathrm{C}$ e umidade relativa média de $65 \%$ ), foram acondicionados em caixas de plástico de dimensões 24,5 x 29,0 x 40,5 cm contendo solo de substrato (Latossolo Vermelho distroférrico típico de textura argilosa), encontrado no campo experimental da Faculdade de Engenharia Agrícola (FEAGRI) da Universidade Estadual de Campinas (UNICAMP). A umidade foi ajustada para $80 \%$ da capacidade de retenção de água (IPT, 1980).

Os corpos de prova foram dispostos verticalmente no solo, com aproximadamente $2 \mathrm{~cm}$ de comprimento acima da superfície do solo (MACHEK et al., 2004). Dos 10 corpos de prova utilizados em cada variável, 6 foram soterrados em solo não estéril e 4 em solo estéril, de acordo com método proposto pelo IPT (1980). A seguir, as caixas foram colocadas em câmara climatizada.

Após um período de 6 semanas, os corpos de prova foram retirados da câmara climatizada e efetuou-se uma inspeção visual. A seguir, eles foram cuidadosamente limpos com o auxílio de um pincel com cerdas macias. Após a estabilização da massa das taliscas ao ar livre, efetuou-se, então, a avaliação parcial da perda de massa e aplicou-se o ensaio de ultrassom às taliscas.

A seguir, as taliscas foram novamente acondicionadas na câmara climatizada por mais 10 semanas, mantendo-se as mesmas condições iniciais. Após esse período final (16 semanas), as taliscas 
foram limpas e secas em estufa até obter-se a constância de massa. A seguir, procedeu-se novamente à pesagem das amostras e foram então efetuados os ensaios não destrutivo (por ultrassom) e destrutivo (flexão estática).

\section{Ultrassom}

O ensaio de ultrassom foi realizado no Laboratório de Ensaios Não Destrutivos (LabEND) da Faculdade de Engenharia Agrícola da UNICAMP, com o auxílio do equipamento de ultrassom Steinkamp BP-7, dispondo de transdutores de seção exponencial de $45 \mathrm{kHz}$ de frequência de ressonância. Os sensores eletroacústicos foram posicionados no centro geométrico da seção transversal das taliscas e, a partir dos valores da velocidade do pulso ultrassônico (VPU), calculou-se o valor do módulo dinâmico (Ed) por meio da equação 1 .

$$
\mathrm{Ed}=\left(\rho \cdot \mathrm{VPU}^{2}\right) \cdot 10^{-9}
$$

Em que: Ed = módulo de elasticidade dinâmico $(\mathrm{GPa})$;

$\rho=$ densidade do material $\left(\mathrm{kg} / \mathrm{m}^{3}\right)$;

$\mathrm{V}=$ velocidade do pulso ultrassônico $(\mathrm{m} / \mathrm{s})$.

\section{Ensaio de flexão estática}

O ensaio de flexão estática foi realizado no Laboratório de Ensaios Destrutivos da Faculdade de Engenharia Agrícola da UNICAMP com auxílio da máquina universal de ensaios mecânicos EMIC DL 30000. Por não haver uma norma específica para avaliar o bambu nessa solicitação, adaptou-se, no que foi possível, a norma NBR 7190/1997, utilizada para o ensaio de madeiras. Os corpos de prova foram posicionados com a camada exterior (mais próxima da casca) voltada para a parte superior, em contato com o cutelo de aplicação da carga. A velocidade de deslocamento do cabeçote foi constante $(2 \mathrm{~mm} / \mathrm{min}$.) e adotou-se um vão livre de $120 \mathrm{~mm}$. O módulo de elasticidade $\left(\mathrm{E}_{\mathrm{m} 0}\right)$ foi obtido por meio da equação 2 . Pelo ensaio, obteve-se um diagrama de carga $(\mathrm{P}$, em $\mathrm{N}$ ) versus deformação (f, em mm) e efetuou-se uma regressão simples, para obter a inclinação do trecho de linearidade $(\Delta \mathrm{P} / \Delta \mathrm{f})$.

$$
\mathrm{E}_{\mathrm{m} 0}=\underbrace{}_{\Delta f 4 \mathrm{bh}^{3}} \cdot 10^{-3}
$$

Em que: $\mathrm{E}_{\mathrm{m} 0}=$ módulo de elasticidade na flexão $(\mathrm{GPa})$;

$\Delta \mathrm{P}=$ variação da carga $(\mathrm{N})$;

$\Delta f=$ variação da flecha $(\mathrm{mm})$;

$\mathrm{b}=$ base $(\mathrm{mm}) ; \mathrm{h}=\operatorname{espessura}(\mathrm{mm}) ; 1=$ vão livre $(\mathrm{mm})$.

O módulo de resistência à flexão (MOR) foi obtido por meio da equação 3:

$$
\mathrm{MOR}=\underline{3 \mathrm{Pl}}
$$

Em que: $\mathrm{MOR}=$ módulo de resistência à flexão $(\mathrm{MPa})$;

$\mathrm{P}=\operatorname{carga}(\mathrm{N}) ; \mathrm{b}=$ base $(\mathrm{mm}) ; \mathrm{h}=\operatorname{espessura}(\mathrm{mm}) ; 1=$ vão livre $(\mathrm{mm})$.

\section{Delineamento estatístico}

A análise estatística foi realizada com auxílio do software STATGRAPHICS Centurion XVI. Adotou-se um delineamento inteiramente casualizado (DIC), e a análise de variância (ANOVA) buscou avaliar o efeito dos fatores (tipo de solo, concentração da solução e duração do tratamento) nas propriedades avaliadas (perda de massa, velocidade do pulso ultrassônico e módulos de ruptura e de elasticidade em flexão estática). As médias foram comparadas pelo teste de Bonferoni, pois o número de repetições das taliscas não era constante, adotando-se o nível de confiança de $95 \%$. 


\section{RESULTADOS E DISCUSSÃO}

\section{Resultados parciais}

Decorridas 6 semanas iniciais do ensaio, a inspeção visual das taliscas não evidenciou alterações importantes devidas à uma possível degradação por fungos, sendo perceptível apenas uma colonização superficial por fungos emboloradores em todas as taliscas (Figura 2).

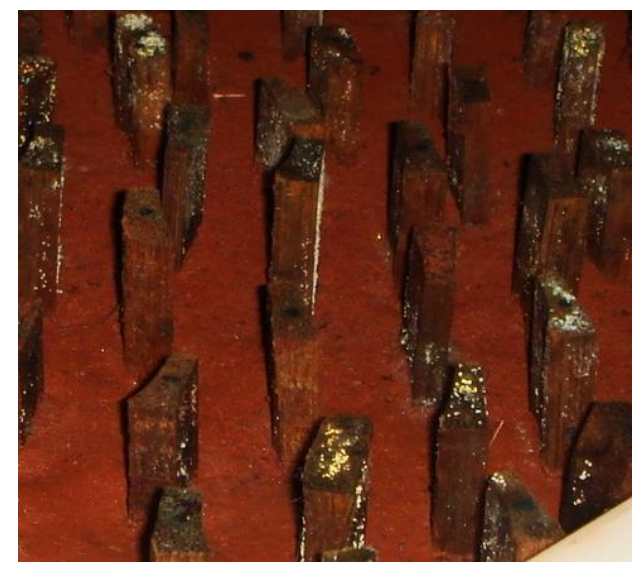

Figura 2. Corpos de prova após 6 semanas de exposição ao ensaio de degradação acelerada.

Figure 2. Specimens after 6 weeks of exposure to accelerated decay test.

Pelo fato de, nessa etapa inicial de 6 semanas de exposição, as taliscas terem sido secadas ao ar (teor de umidade em torno de 10\%), não foi possível detectar uma possível perda de massa que pudesse ser atribuída a um suposto ataque de fungos, pois, no início do experimento, as taliscas, após serem submetidas aos distintos tratamentos, haviam sido secadas em estufa até obter-se a constância em massa. Outro fator a ser considerado deve-se também ao limitado período de tempo de exposição das taliscas, não havendo provavelmente condições propícias para ocorrer uma colonização e degradação efetiva do bambu por parte dos fungos.

Da mesma forma, a avaliação das taliscas por ultrassom indicou uma diminuição significativa do módulo dinâmico (Ed) em relação aos valores iniciais, porém podendo atribuir-se essa aparente degradação da talisca à influência da umidade - quanto maior o teor de umidade, menor a velocidade do pulso ultrassônico e, consequentemente, menor seria o módulo dinâmico.

\section{Ensaios não destrutivos}

Após16 semanas de exposição das taliscas, realizou-se uma inspeção visual, na qual também se observou novamente apenas a presença de pequenas manchas escuras em algumas amostras (Figura 3), indicando, provavelmente, um ataque de fungos, porém ainda em uma fase inicial, o que teoricamente não comprometeria estruturalmente as taliscas.

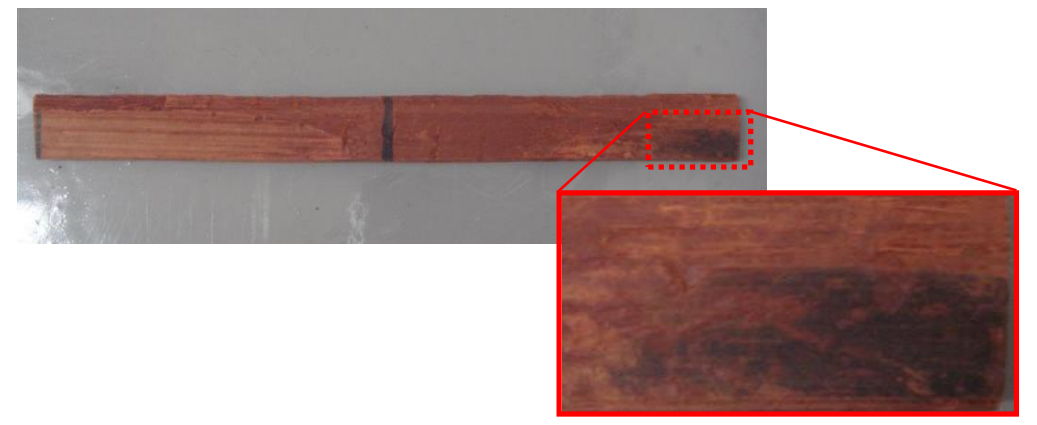

Figura 3. Corpos de prova após 16 semanas de exposição ao ensaio de apodrecimento acelerado.

Figure 3. Specimens after 16 weeks of exposure to accelerated decay test. 
As manchas escuras foram observadas principalmente nas regiões dos corpos de prova que não estavam enterradas no solo e em amostras expostas ao solo natural para todos os grupos avaliados, independentemente da concentração da solução e do tempo de imersão ao qual foram submetidas as taliscas.

Apesar das manchas observadas na superfície das taliscas, elas se mostravam ainda aparentemente intactas e sem apresentarem nenhum sinal evidente de deterioração por parte dos fungos.

Vários fatores podem interferir nos resultados obtidos, cabendo, portanto, tecer alguns comentários quanto à aparente inadequação da metodologia adotada para avaliar esse tipo de material por meio de ensaios não destrutivos:

a) Perda de massa: o experimento não foi conduzido em ambiente perfeitamente controlado, conforme adotado por Paes et al. (2009). Desse modo, o tempo necessário para ocorrer a estabilização em massa das taliscas, ou seja, após elas alcançarem a umidade de equilíbrio ao ambiente (em torno de $10 \%$ ), dependia das condições ambientais (temperatura e umidade relativa do ar). Por outro lado, antes de se iniciar o experimento, as taliscas foram secas em estufa até constância de massa, mas se o mesmo procedimento fosse adotado após 6 semanas de exposição, haveria um risco de proceder-se a um tipo de esterilização da talisca, devido à provável morte dos fungos que eventualmente estariam se desenvolvendo na sua superfície. Tal fato inviabilizaria a avaliação do efeito do ataque ao longo do tempo de exposição, pois as mesmas taliscas avaliadas após 6 semanas retornaram para permanecerem durante mais 10 semanas de exposição. Uma alternativa que poderia ser adotada seria a de aumentar significativamente a quantidade de taliscas a serem ensaiadas, consideradas idênticas entre si, e, a seguir, retirar lotes parciais delas, para, após a secagem em estufa, efetuar os ensaios não destrutivo e destrutivo.

Outro aspecto a ser considerado refere-se aos tipos de fungos aos quais as taliscas foram expostas e de sua interação com o tipo de material lignocelulósico testado. A podridão mole - responsável pela perda de massa de materiais lignocelulósicos, se mostrou mais efetiva na degradação de madeiras folhosas, quando comparadas com uma espécie de madeira conífera (PAES et al., 2009), não se conhecendo, porém, qual seria seu efeito na degradação do bambu. No entanto, a exemplo de outras monocotiledôneas, o bambu, por sua constituição química, torna-se alvo do ataque de agentes biodegradadores, que se alimentam dos seus nutrientes. Quando colocado em meio úmido (de 20 a $30 \%$ de umidade), o bambu encontra-se sujeito ao ataque de fungos manchadores e emboloradores.

b) Velocidade do pulso ultrassônico: a propagação das ondas ultrassônicas se faz principalmente ao longo dos feixes de fibras, que são os elementos de maior densidade e de maior durabilidade natural do bambu. Desse modo, acredita-se que, mesmo para taliscas que estivessem extremamente degradadas, não haveria mudança significativa no tempo de propagação da onda ultrassônica, e, portanto, a velocidade de propagação dessas ondas não sofreria mudanças significativas. Além disso, as magnitudes tanto da densidade aparente quanto da velocidade de propagação do pulso ultrassônico (necessárias para o cálculo do módulo de elasticidade) através das taliscas dependem fortemente do teor de umidade: a primeira lhe é diretamente proporcional, enquanto que a segunda varia com o seu inverso, até certo limite, o ponto de saturação das fibras ao ar (para o caso do bambu, situa-se em torno de 20\%). Provavelmente, resultados mais adequados seriam obtidos (caso as taliscas se mostrassem degradadas por fungos), se fossem utilizados equipamentos mais apropriados, com os sensores posicionados na seção transversal das taliscas. Nesse caso, seria mais apropriada a utilização de sensores eletroacústicos de maior frequência de ressonância (de $1 \mathrm{MHz}$, por exemplo).

c) Usinagem das taliscas: devido à usinagem preliminar, teoricamente as taliscas seriam naturalmente mais resistentes ao ataque de organismos xilófagos, demandando, portanto, maior tempo de exposição para que se pudesse observar um possível efeito degradador devido à ação de fungos. A constituição química do material avaliado também exerce grande influência em sua durabilidade: para as madeiras, o teor em extrativos pode influenciar sua durabilidade ao ataque de organismos xilófagos (PAES et al., 2009). Os mesmos autores, analisando espécies do semiárido nordestino, obtiveram até $35 \%$ de perda em massa para madeiras retiradas da região do alburno, que é a região mais sensível da madeira ao ataque de organismos xilófagos. No entanto, para o caso do bambu, não foram encontradas na literatura informações a respeito da sua degradação em função da posição de amostragem em relação à parede do colmo.

d) Tratamento em água quente: além de as taliscas poderem ser naturalmente mais resistentes, conforme relatado no item anterior, em realidade efetuou-se um tratamento combinado das mesmas. Além de uma possível absorção do ácido pirolenhoso pelas células do bambu, e mesmo o recobrimento 
superficial das taliscas por esse produto, a própria ação da água aquecida poderia proporcionar a obtenção de taliscas mais resistentes à degradação, devido à extração ou degradação parcial do amido contido nas células parenquimáticas.

e) Tempo de exposição: acredita-se que, aliado aos fatores anteriormente descritos, o tempo de exposição ainda não tenha sido suficiente para propiciar um ataque efetivo das taliscas por partes dos fungos. Espelho e Beraldo (2008) e Paes et al. (2009) utilizaram, na avaliação da degradação de bambu e de madeiras do semiárido nordestino, 13 meses e 6 meses, respectivamente, períodos esses muito superiores àqueles utilizados neste experimento (de 6 e 16 semanas). Para esse período de exposição de até 16 semanas, os diversos tratamentos aplicados às taliscas se mostraram eficientes.

\section{Ensaio de flexão estática}

a) Módulo de elasticidade $\left(\mathrm{E}_{\mathrm{m} 0}\right)$

A análise de variância aplicada aos resultados do módulo de elasticidade $\left(\mathrm{E}_{\mathrm{m} 0}\right)$ em flexão estática indicou a influência, ao nível de $95 \%$ de probabilidade estatística, dos fatores concentração e tempo de tratamento e da interação entre esses dois fatores. Nessa propriedade, o fator tipo de solo não se mostrou significativo (Tabela 1).

Conforme apresentado na tabela 2, aparentemente uma possível degradação da talisca se mostrou mais evidenciada pelo módulo de ruptura em flexão (MOR), que foi mais sensível ao efeito dos fatores testados. Mesmo a influência da concentração da solução situou-se muito próxima ao valor estatístico testado $(5 \%)$.

Tabela 1. Análise de variância (ANOVA) para $\mathrm{E}_{\mathrm{m} 0}$ - Soma dos quadrados Tipo III.

Table 1. Analysis of Variance (ANOVA) for $\mathrm{E}_{\mathrm{m} 0}$ - Type III Sum of Squares.

\begin{tabular}{lccccc}
\hline Fonte & $\begin{array}{c}\text { Soma dos } \\
\text { quadrados }\end{array}$ & GL & Quadrado médio & Teste F & Probabilidade \\
\hline Efeitos principais & 1.78217 & 1 & 1.78217 & 0.20 & 0.6540 \\
A:Solo & 189.767 & 4 & 47.4417 & 5.37 & 0.0004 \\
B:Concentração & 107.45 & 3 & 35.8166 & 4.05 & 0.0083 \\
C:Tempo & & & & & \\
Interações & 40.3439 & 4 & 10.086 & 1.14 & 0.3391 \\
AB & 34.4564 & 3 & 11.4855 & 1.30 & 0.2765 \\
AC & 307.992 & 12 & 25.666 & 2.90 & 0.0012 \\
BC & 1405.09 & 159 & 8.83701 & & \\
Resíduo & 2082.22 & 186 & & & \\
Total (corrigido) & & & & & \\
\hline
\end{tabular}

Tabela 2. Análise de variância (ANOVA) para MOR - Soma dos quadrados Tipo III.

Table 2. Analysis of Variance (ANOVA) for MOR - Type III Sum of Squares.

\begin{tabular}{lccccc}
\hline Fonte & $\begin{array}{c}\text { Soma dos } \\
\text { quadrados }\end{array}$ & GL & Quadrado médio & Teste F & Probabilidade \\
\hline Efeitos principais & 14478.3 & 1 & 14478.3 & 42.54 & 0.0000 \\
A:Solo & 2794.47 & 4 & 698.618 & 2.05 & 0.0894 \\
B:Concentração & 7337.59 & 3 & 2445.86 & 7.19 & 0.0001 \\
C:Tempo & & & & & \\
Interações & 1746.5 & 4 & 436.626 & 1.28 & 0.2788 \\
AB & 247.504 & 3 & 82.5013 & 0.24 & 0.8666 \\
AC & 12198.0 & 12 & 1016.5 & 2.99 & 0.0008 \\
BC & 55816.9 & 164 & 340.347 & & \\
Resíduo & 94999.3 & 191 & & & \\
Total (corrigido) & & & & & \\
\hline
\end{tabular}

Conforme apresentado em ambas as tabelas, o período de imersão das taliscas na solução (tempo) aparentou ser o fator de maior importância nas propriedades avaliadas. 
Nas tabelas 3 e 4, apresentam-se, respectivamente, para $\mathrm{E}_{\mathrm{m} 0}$ e MOR, as comparações entre as médias, pelo teste de Bonferoni, ao nível de $95 \%$ de probabilidade estatística.

Conforme descrito na Tabela 1, o tipo de solo (natural ou estéril) não influenciou o valor do $\mathrm{E}_{\mathrm{m} 0}$. Para as soluções com menor concentração de ácido pirolenhosos, observou-se uma tendência à diminuição do $\mathrm{E}_{\mathrm{m} 0}$ após os tratamentos com menor duração. Para a solução com maior concentração (30\%), o tempo de tratamento não apresentou interferência, provavelmente devido à maior dificuldade em obter-se a impregnação das taliscas em soluções mais concentradas. No entanto, observou-se tendência na

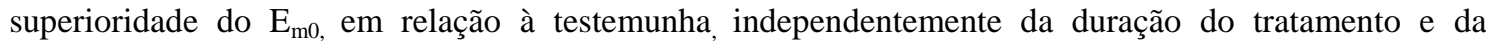
concentração da solução. Considerando-se que não se observou perda significativa de massa das taliscas, e que a resistência mecânica de um material depende diretamente dessa propriedade, poder-se-ia otimizar o $\mathrm{E}_{\mathrm{m} 0}$ a partir do tempo de tratamento e da duração do tratamento que fossem considerados ideais. No entanto, observa-se na tabela 3 que existem várias combinações possíveis desses fatores que permitiriam a obtenção de valores similares do $\mathrm{E}_{\mathrm{m} 0}$. Dessa forma, seria necessário efetuar-se uma análise econômica, considerando-se os custos do ácido pirolenhoso e do aporte energético para o aquecimento da solução. Levando em conta que a combinação ideal seria aquela que contemplasse a menor concentração de ácido pirolenhoso com o menor tempo de tratamento, sem que o valor de $\mathrm{E}_{\mathrm{m} 0}$ fosse reduzido substancialmente, uma possível escolha seria a concentração de $10 \%$ e duração de tratamento de 90 min.

Quanto ao MOR, observou-se uma tendência clara de ocorrer maior degradação nas taliscas colocadas em solo normal, quando comparadas com aquelas colocadas em solo estéril. Para o solo estéril, observou-se maior tendência ao efeito positivo de utilizarem-se tratamentos com maior duração. Porém essa tendência foi menos evidente para o caso da utilização do solo natural.

Tabela 3. Comparação entre as médias de $\mathrm{E}_{\mathrm{m} 0}$ (em GPa).

Table 3. Comparison between $\mathrm{E}_{\mathrm{m} 0}$ averages (in GPa).

\begin{tabular}{lcccc}
\hline \multirow{2}{*}{ Concentração (\%) } & \multicolumn{3}{c}{ Duração } & \\
& $\mathbf{1 5}$ min. & $\mathbf{4 5}$ min. & $\mathbf{9 0}$ min. & $\mathbf{1 8 0}$ min. \\
\hline 0 & $14,61^{\mathrm{ab} *}$ & $12,62^{\mathrm{a}}$ & $14,86^{\mathrm{b}}$ & $14,85^{\mathrm{b}}$ \\
5 & $15,77^{\mathrm{a}}$ & $13,28^{\mathrm{ab}}$ & $15,77^{\mathrm{ab}}$ & $16,13^{\mathrm{b}}$ \\
10 & $20,12^{\mathrm{b}}$ & $13,13^{\mathrm{a}}$ & $16,65^{\mathrm{b}}$ & $18,10^{\mathrm{b}}$ \\
20 & $15,17^{\mathrm{ab}}$ & $14,64^{\mathrm{b}}$ & $17,66^{\mathrm{b}}$ & $13,55^{\mathrm{b}}$ \\
30 & $15,03^{\mathrm{a}}$ & $17,39^{\mathrm{a}}$ & $16,69^{\mathrm{a}}$ & $17,73^{\mathrm{a}}$ \\
\hline
\end{tabular}

*Médias seguidas da mesma letra na horizontal não diferem estatisticamente ao nível de $95 \%$ de probabilidade.

Tabela 4. Comparação entre as médias de MOR (em MPa).

Table 4. Comparison between MOR averages (in MPa).

\begin{tabular}{llccc}
\hline \multirow{2}{*}{ Solo } & \multicolumn{3}{c}{ Duração } & \\
& $\mathbf{1 5}$ min. & $\mathbf{4 5}$ min. & $\mathbf{9 0}$ min. & $\mathbf{1 8 0}$ min. \\
\hline Estéril & $133,22^{\mathrm{ab}}$ & $125,02^{\mathrm{a}}$ & $141,75^{\mathrm{b}}$ & $140,55^{\mathrm{b}}$ \\
Natural & $120,54^{\mathrm{ab}}$ & $116,20^{\mathrm{ab}}$ & $110,12^{\mathrm{a}}$ & $123,77^{\mathrm{b}}$ \\
\hline
\end{tabular}

* Médias seguidas da mesma letra na horizontal não diferem estatisticamente ao nível de $95 \%$ de probabilidade.

\section{CONCLUSÕES}

Baseado nas condições sob as quais se desenvolveu este experimento, concluiu-se que:

- Os ensaios não destrutivos por meio da avaliação de perda de massa das taliscas e por meio de ultrassom, após 6 e 16 semanas de exposição das taliscas, não permitiram determinar a influência dos fatores tipo de solo, concentração da solução e duração do tratamento.

- Após 16 semanas de exposição das taliscas, o tipo de solo (natural ou estéril) não influenciou o módulo de elasticidade $\left(\mathrm{E}_{\mathrm{m} 0}\right)$. Ocorreu uma tendência da influência positiva nessa propriedade da duração do tratamento e do aumento da concentração da solução até $20 \%$.

- Após 16 semanas de exposição das taliscas, o tipo de solo influenciou o MOR. Ocorreu uma tendência da influência positiva nessa propriedade com relação à duração do tratamento. A concentração da solução não influenciou essa propriedade. 


\section{AGRADECIMENTOS}

À CAPES/CNPq, pela bolsa concedida; à empresa Oré Brasil, pelo apoio material; ao Prof. Dr. Julio Soriano, à doutoranda Michelle S. Rodrigues e à professora Gisleiva C. S. Ferreira, pelo suporte técnico.

\section{REFERÊNCIAS}

ALVES, M. V. S.; MENDES, A. S. Biodegradação e preservação da madeira. Brasília: LPF, 2002. $40 \mathrm{p}$.

ALVES, M.; CAZETTA, J. O.; NUNES, M. A.; OliVEIRA, C. A. L.; COLOMBI, C. A. Ação de diferentes preparações de extrato pirolenhoso sobre Brevipalpus phoenicis (GEIJSKES). Revista Brasileira de Fruticultura. Jaboticabal, SP, v. 29, n. 2, p. 382 - 385, 2007.

ASSOCIAÇÃO BRASILEIRA DE NORMAS TÉCNICAS (ABNT) - NBR 7190. Projeto de estruturas de madeira. Rio de Janeiro, 1997.

ESPELHO, J. C. C.; BERALDO, A. L. Avaliação físico-mecânica de colmos de bambu tratados. Revista Brasileira de Engenharia Agrícola e Ambiental, Campina Grande, PB, v. 12, n. 6, p. 645 - 652, 2008.

INSTITUTO DE PESQUISAS TECNOLÓGICAS DO ESTADO DE SÃO PAULO (IPT). IPT 1.157 parte D5: Métodos de ensaios e análises em preservação de madeiras: Ensaio acelerado de laboratório para determinação de eficiência de preservativos contra fungos de podridão mole. São Paulo, 1980. 2 p.

MACHEK, L.; EDLUND, M. L.; SIERRA-ALVAREZ, R.; MILITIZ, H. A non-destructive approach for assessing decay in preservative treated wood. Wood Science and Technology, v. 37, p. 411 - 417, 2004.

PAES, J. B.; MORAIS, V. M.; LIMA, C. R.; SANTOS, J. C. Resistência natural de nove madeiras do semiárido brasileiro a fungos xilófagos em simuladores de campo. Árvore, Viçosa, MG, v. 33, n. 3, p. 511 - 520, 2009.

PEREIRA, M. A. R.; BERALDO, A. L. Bambu de corpo e alma. Bauru, Canal 6 Editora, 2007. 222 p.

PORTO, P. R.; SAKITA, A. E. N.; SAKITA, M. N. Efeito da aplicação do extrato pirolenhoso na germinação e no desenvolvimento de mudas de Pinus elliottii var. elliottii. IF Série Registros, São Paulo, n. 31, p. $15-19,2007$.

RIVERO, L. A. Laminado colado e contraplacado de bambu. 99 f. Dissertação (Mestrado em Engenharia Agrícola) - Faculdade de Engenharia Agrícola, Universidade Estadual de Campinas, São Paulo, 2003.

SOUZA, J. M. F.; MORAES, S. R. P.; GOMES, R. C. C.; ARAÚJO JR., E. R. M.; AMARAL, A. G.; ALVES, J. D. Resistência à tração e compressão do bambu Dendrocalamus giganteus após tratamento de mineralização. In: SEMINÁRIO DE INICIAÇÃO CIENTÍFICA, 5, 2007, Anápolis. Anais... GO, Universidade Estadual de Goiás, 2007, p. 1 - 5.

SOUZA-SILVA, A.; ZANETTI, R.; CARVALHO, G. A.; SANTOS, A.; MATTOS, J. O. S. Preferência de formigas-cortadeiras por mudas de eucalipto pulverizadas ou imersas em soluções de extrato pirolenhoso em diferentes concentrações. Scientia Forestalis, Piracicaba, SP, n. 67, p. 9 - 13, 2005.

ZANETTI, M.; CAZETTA, J. O.; MATTOS JR., D.; CARVALHO, S. A. Uso de subprodutos de carvão vegetal na formação do porta-enxerto limoeiro 'cravo' em ambiente protegido. Revista Brasileira de Fruticultura, Jaboticabal, SP, v. 25, n. 3, p. 508 - 512, 2003. 
